\title{
THE SECOND INTERNATIONAL CONGRESS IN PHILOSOPHY, PHENOMENOLOGY, AND THE SCIENCES OF LIFE GDANSK, POLAND JUNE 5TH TILL 9TH, 1997
}

\author{
Call for papers \\ Interdisciplinary Investigations pertaining to all fields of \\ Scholarship, Literature, Fine Arts
}

Organiser: The World Institute For Advanced Phenomenological Research and Learning

Hosted by : The Polytechnical University of Gdansk

Topic: Origins of Life, Individuation, Evolution of Types, the New Critic of Reason and Human Creative Condition

Registration fee : US\$ 150 : 00

Abstracts by January 1st, 1997; papers by April 1st, 1997 to be sent to Professor Anna-Teresa Tymieniecka, Program Director, The World Phenomenology Institute, 348 Payson Rd., Belmont, MA, 02178/USA. 